\title{
Immunity to larval Brugia malayi in BALB/c mice: protective immunity and inhibition of larval development.
}

\author{
D. Abraham \\ Thomas Jefferson University \\ R. B. Grieve \\ Colorado State University, \\ J. M. Holy \\ University of Wisconsin Madison \\ B. M. Christensen \\ University of Wisconsin Madison
}

Follow this and additional works at: https://jdc.jefferson.edu/mifp

Part of the Medicine and Health Sciences Commons

Let us know how access to this document benefits you

\section{Recommended Citation}

Abraham, D.; Grieve, R. B.; Holy, J. M.; and Christensen, B. M., "Immunity to larval Brugia malayi in BALB/c mice: protective immunity and inhibition of larval development." (1989). Department of Microbiology and Immunology Faculty Papers. Paper 137.

https://jdc.jefferson.edu/mifp/137

This Article is brought to you for free and open access by the Jefferson Digital Commons. The Jefferson Digital Commons is a service of Thomas Jefferson University's Center for Teaching and Learning (CTL). The Commons is a showcase for Jefferson books and journals, peer-reviewed scholarly publications, unique historical collections from the University archives, and teaching tools. The Jefferson Digital Commons allows researchers and interested readers anywhere in the world to learn about and keep up to date with Jefferson scholarship. This article has been accepted for inclusion in Department of Microbiology and Immunology Faculty Papers by an authorized administrator of the Jefferson Digital Commons. For more information, please contact: JeffersonDigitalCommons@jefferson.edu. 


\title{
IMMUNITY TO LARVAL BRUGIA MALAYI IN BALB/C MICE: PROTECTIVE IMMUNITY AND INHIBITION OF LARVAL DEVELOPMENT
}

\author{
DAVID ABRAHAM, ROBERT B. GRIEVE, JON M. HOLY, AND \\ BRUCE M. CHRISTENSEN \\ Thomas Jefferson University, Philadelphia, Pennsylvania, \\ Colorado State University, Fort Collins, Colorado; and \\ University of Wisconsin-Madison, Madison, Wisconsin
}

\begin{abstract}
The objective of this study was to analyze the immune response of mice to the larval stages of Brugia malayi. Male BALB/c mice were inoculated with 3 doses of irradiated third-stage larvae (L-3) of $B$. malayi and were subsequently challenged with L-3 implanted ip within diffusion chambers. After 3 weeks, larvae were recovered to determine their viability, length, and stage of development. A significant reduction in parasite survival was observed in immunized mice. Furthermore, larvae recovered from immunized mice were significantly shorter than larvae recovered from control mice. All larvae recovered from immunized mice were L-3, whereas $96 \%$ of larvae recovered from controls were fourth-stage larvae (L-4). Sera collected from control and immunized mice were tested for the presence of antibodies reactive with L-3 and L-4 antigens using an indirect fluorescent antibody assay employing frozen larval cross-sections as antigen. Sera recovered after challenge of control mice reacted with internal, but not surface, antigens of L-3 and L-4. Alternatively, sera from immunized mice reacted with both internal and external antigens of both L-3 and L-4.
\end{abstract}

Protective immunity to infection with Brugia malayi has been demonstrated in 2 rodent hosts, jirds and mice. Jirds were assessed for protective immunity by determining the number of adult worms recovered following challenge. Immunization consisted of a single subcutaneous inoculation of $15 \mathrm{Krad}$ irradiated third-stage larvae (L-3). Eight weeks after immunization, the jirds were infected ip with L-3. Approximately $14 \%$ of L-3 injected into control jirds were recovered as adults, whereas only $1 \%$ were recovered from immunized jirds. This immunization regimen was thus successful at producing a $91 \%$ reduction in parasite survival.' Jirds have also been immunized against $B$. malayi using microfilarial antigens. Approximately $27 \%$ of L-3 injected into control jirds in this experiment were recovered as adults, whereas only $14 \%$ of challenge larvae were recovered from immunized jirds. This immune-mediated elimination of parasites in immunized jirds was only effective against female worms; equal numbers of male worms were recovered from control and immunized hosts. ${ }^{2}$

BALB/c mice were immunized by 3 sc injections of irradiated $(20 \mathrm{Krad}) B$. malayi $\mathrm{L}-3$. One week after the final immunization, mice were challenged by ip injection of 100 normal B. malayi L-3. Two weeks after challenge, $15 \%$ of larvae injected into control mice were recovered live, whereas only approximately $1 \%$ were recovered from immunized mice. ${ }^{3}$ In another study, BALB/c mice were immunized by ip inoculations of non-irradiated worms. Challenge infections consisted of 50 L-3 injected ip. It was determined that about $20 \%$ of larvae injected into control mice survived for approximately 10 days, after which there was a rapid decline in the number of larvae recovered. In this study, resistance was evidenced following immunization by an accelerated elimination of challenge larval infections. Similar resistance to larval $B$. malayi was observed in mice immunized with live or dead L-3, or live fourth-stage larvae (L-4), male adult worms, female adult worms, or microfilariae. ${ }^{4}$

Studies on the development of larval filarids and on immunity to filarial larvae have been hindered by the difficulty of recovering larvae after inoculation into either natural or experimental definitive hosts. To overcome this obstacle, diffusion chambers have been utilized. This procedure places larvae in an in vivo environment yet still allows them to be completely and 
efficiently recovered. Diffusion chambers have been used to maintain $B$. pahangi ${ }^{5}$ and Onchocerca volvulus ${ }^{6}$ in vivo, and to study immune responses to larvae of Dipetalonema vitea $e^{7.8}$ and Dirofilaria immitis. 9.10

The objective of the present study was to analyze the development of protective immunity to larval B. malayi confined within diffusion chambers. BALB/c mice were immunized using a previously described protocol ${ }^{3}$ and larval survival and development were assessed in control and immunized mice. Additionally, antibody responses to larval antigens were investigated to determine if a relationship existed between the patterns and intensity of antibody binding and immune protection.

\section{MATERIALS AND METHODS}

Aedes aegypti Liverpool (Blackeye strain) were infected with $B$. malayi by feeding on infected, anesthetized jirds originally obtained from the U.S.-Japan Cooperative Medical Science Program. Two weeks after infection, mosquitoes were surface sterilized in $95 \%$ ethanol followed by $1 \%$ benzalkonium chloride and were then placed on screens within culture medium filled funnels as previously described. ${ }^{8}$ L-3, collected from the funnels after $90 \mathrm{~min}$, were placed in syringes, irradiated with $20 \mathrm{Krad}$ gamma-radiation from a cesium-137 source and then injected subcutaneously into 10 week old male BALB/c mice (Jackson Laboratories, Bar Harbor, ME).

Immunization experiments were performed twice with differences between the 2 immunization regimens due to the availability of L-3. The immunization protocol used in Exp. 1 was: Day 0, 100 L-3; Day 14, 100 L-3; and Day 28, $30 \mathrm{~L}-3$. The immunization protocol used in Experiment 2 was Day 0, 100 L-3; Day 14, 40 L-3; and Day 28, 40 L-3. In both experiments, challenge took place on Day 35 and necropsy on Day 56. Five mice were immunized in Exp. 1 and 3 in Exp. 2; 5 naive mice receiving challenge infections were used in each of the experiments. Challenge infections consisted of 20 L-3 implanted ip within diffusion chambers. Diffusion chambers were constructed from $14 \mathrm{~mm}$ lucite rings covered with $5 \mu \mathrm{m}$ pore size hydrophilic Durapore membranes (Millipore, Bedford, MA) as previously described. ${ }^{8}$

At the time of necropsy, mice were anesthe- tized with methoxyflurane and then cervically dislocated. Diffusion chambers were recovered and the viable larvae counted. The recovered larvae were pooled by experimental group and then placed into glacial acetic acid followed by $70 \%$ ethanol containing $5 \%$ glycerin. The ethanol was allowed to evaporate, leaving the larvae in glycerin. Larvae were then measured by tracing their projected images with an opisometer. Larval stages were determined by the shape of the larval anterior end, as previously described." A total of 58 larvae from control mice and 34 from immunized mice were measured and analyzed to determine the state of larval development.

Blood samples were collected from control and immunized mice prior to the implantation of the diffusion chambers and at the time of necropsy. Serum was separated from clotted blood by centrifugation and stored at $-80^{\circ} \mathrm{C}$. Frozen sections of L-3 and L-4 were prepared to test for the presence of antibodies in the mouse serum to larval antigens. L-3 were obtained as described above; L-4 were obtained from diffusion chambers that had been implanted in normal mice for 18 days. Larvae were embedded in O.C.T. compound (Miles Scientific, Naperville IL) and frozen on dry ice. Cryostat sections $10 \mu \mathrm{m}$ thick were collected on gelatin coated slides and stored at $-40^{\circ} \mathrm{C}$. Prior to labeling, sections were allowed to equilibrate to room temperature, and were then air dried for $15 \mathrm{~min}$. Sections were permeabilized with $0.2 \%$ Triton- $\mathrm{X}$ in phosphate buffered saline (PBS) for $15 \mathrm{~min}$ at room temperature, briefly rinsed in PBS, and then incubated in neat goat serum for $1 \mathrm{hr}$ at $37^{\circ} \mathrm{C}$. Sera from individual control and experimental mice were diluted $1: 10$ in PBS containing 5\% normal goat serum and then added to the sections of L-3 or L-4 for $1 \mathrm{hr}$ at $37^{\circ} \mathrm{C}$. The slides were washed 3 times in PBS for $5 \mathrm{~min}$ and incubated with a 1:300 dilution of FITC conjugated IgG fraction of goat anti-mouse IgM, IgG, and IgA (Cooper Biomedical, West Chester, PA) for $1 \mathrm{hr}$ at $37^{\circ} \mathrm{C}$. After 3 washes in PBS, slides were coverslipped with $90 \%$ glycerol in PBS with $0.1 \%$ p-phenylenediamine. To aid in the comparison of fluorescence between slides, photographs of sections were taken using equal exposure times, and the negatives subsequently compared for intensity of reaction. Photomicrographs used for the figures in this report used exposures that would best demonstrate the areas of fluorescence not the degree of fluorescence. Immunofluorescence 
TABLE 1

Survival and growth of larval Brugia malayi in control and immunized mice

\begin{tabular}{lcc}
\hline & Control & Immune \\
\hline Exp. 1 & 15 & 11 \\
No. recovered larvae* & 12 & 11 \\
& 9 & 11 \\
& 7 & 5 \\
Mean \% recovery & 4 & 6 \\
Mean larval length (mm) & $47 \pm 21$ & $44 \pm 15$ \\
Exp. 2 & $2.87 \pm 0.93(33) \dagger$ & $1.79 \pm 0.16(25)$ \\
No. recovered larvae & & 13 \\
& 20 & 7 \\
& 16 & 5 \\
Mean \% recovery & 16 & \\
Mean larval length $(\mathrm{mm})$ & 15 & $42 \pm 21$ \\
\hline
\end{tabular}

* Number of larvae recovered out of an initial inoculum of 20.

+ Number of larvae measured.

was evaluated on a scale of $(1)+-(4)+$ (weak diffuse fluorescence to brilliant fluorescence).

Statistical analyses of larval recovery and growth were accomplished using Student's $t$-test.

\section{RESULTS}

Larvae recovered 3 weeks after implantation in control and immunized mice were assessed for viability and development. Of larvae implanted in control mice in both experiments, $65 \%$ $\pm 24 \%$ were recovered live, as compared to $43 \%$ $\pm 16 \%$ of larvae from immunized mice (Table 1). This reduction of $34 \%$ in parasite survival was statistically significant $(P=0.041)$. Cellular adherence to the larval surface was a rare finding

TABLE 2

Relative antibody levels in the serum of control and immunized mice to the surface and internal antigens of Brugia malayi $L-3$ and $L-4$

\begin{tabular}{|c|c|c|c|c|}
\hline & \multicolumn{2}{|c|}{ Control } & \multicolumn{2}{|c|}{ Immune } \\
\hline & $\begin{array}{l}\text { Pre- } \\
\text { chal- } \\
\text { lenge }\end{array}$ & $\begin{array}{l}\text { Post- } \\
\text { chal- } \\
\text { lenge }\end{array}$ & $\begin{array}{l}\text { Pre- } \\
\text { chal- } \\
\text { lenge }\end{array}$ & $\begin{array}{l}\text { Post- } \\
\text { chal- } \\
\text { lenge }\end{array}$ \\
\hline \multicolumn{5}{|l|}{$\mathrm{L}-3$} \\
\hline Surface & - & - & ++ & $++t+$ \\
\hline Internal & - & + & ++ & ++++ \\
\hline \multicolumn{5}{|l|}{ L-4 } \\
\hline Surface & - & - & ++ & +++ \\
\hline Internal & - & + & ++ & $+t+$ \\
\hline
\end{tabular}

for larvae recovered from both control and immunized mice. A significant difference in larval lengths was noted between larvae recovered from control mice and those recovered from immunized mice. L-3 measured directly after emergence from mosquitoes were $1.50 \pm 0.16 \mathrm{~mm}$ long. Larvae recovered from control mice from both experiments were $2.97 \pm 0.86 \mathrm{~mm}$ long, whereas larvae from immunized mice were only $1.88 \pm 0.33 \mathrm{~mm}$ long $(P=0.000$; Table 1$)$. The percentage of larvae which developed from L-3 to L-4 was determined to be $96 \%$ for larvae recovered from control mice. In contrast, all larvae recovered from immunized mice were still L-3.

Antibodies binding to frozen sections of $\mathrm{L}-3$ and L-4 were analyzed with serum collected from individual control and immune mice pre- and post-challenge. The results, summarized in Table 2, show that cryostat sections of L-3 and L-4 incubated in normal mouse sera displayed only a faint diffuse background fluorescence. After challenge, each control mouse produced a low level antibody response to internal antigens of both L-3 and L-4 (Fig. 1), but not to the surface of the larvae. No differences were noted in the antibody binding patterns to L-3 and L-4. Immunized mice produced moderate levels of antibody to both surface and internal antigens of L-3 and L-4 prior to challenge. After challenge, antibody binding to surface and internal antigens increased significantly (Fig. 2). Antibodies de- 


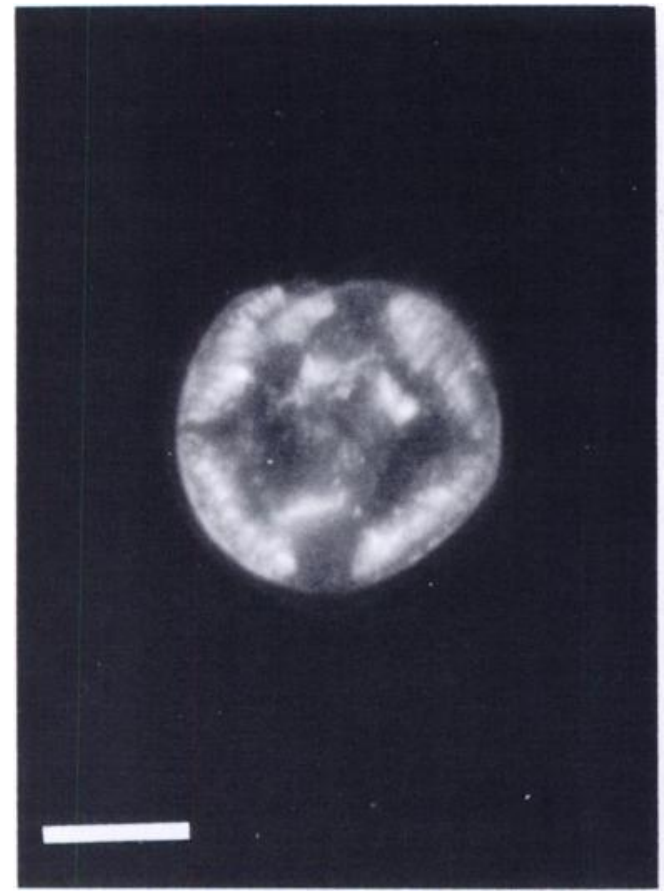

FIGURE 1. Indirect fluorescent antibody assay on cryostat section of $B$. malayi $\mathrm{L}-4$ using sera collected from control mice following challenge. Similar results were obtained with $\mathrm{L}-3$. Bar $=10 \mu \mathrm{m}$.

rived from all immune mice bound to $\mathrm{L}-3$ and L-4 in an identical pattern.

\section{DISCUSSION}

B. malayi larvae survived in the peritoneal cavities of BALB/c mice for at least 3 weeks when implanted within diffusion chambers. Previous studies, in which larvae were inoculated directly into the peritoneal cavity of $\mathrm{BALB} / \mathrm{c}$ mice, reported significantly fewer live larvae recovered after shorter infection durations. ${ }^{3.4}$ It is possible that the diffusion chambers provided a suitable environment for larval development in a normally insusceptible host, as has been suggested for the larvae of $D$. immitis in BALB/c mice. ${ }^{12}$ Alternatively, larval recoveries from diffusion chambers may reflect a more accurate representation of the total number of larvae actually surviving within a host, in comparison to results obtained using other larval recovery methods. When B. malayi L-3 were implanted for $48 \mathrm{hr}$ in diffusion chambers in the peritoneal cavities of Mastomys natalensis, rats, or jirds, recovery

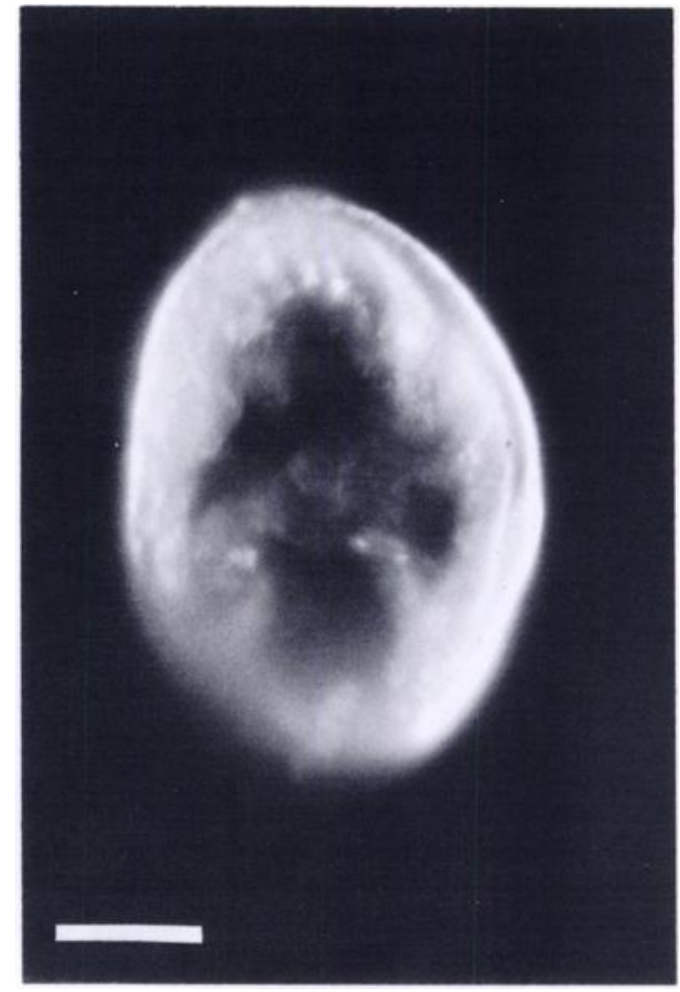

FIGURE 2. Indirect fluorescent antibody assay on cryostat section of $B$. malayi $\mathrm{L}-3$ using sera collected from immunized mice following challenge. Similar results were obtained with L-4. Bar $=10 \mu \mathrm{m}$.

rates of $35 \%, 24 \%$, and $100 \%$ were obtained, respectively. ${ }^{13}$ Survival rates reported in the present study suggest that BALB/c mice, unlike $M$. natalensis and rats, are not resistant to infection with larval $B$. malayi.

A significant reduction in parasite survival was observed in challenge infections implanted in mice immunized with irradiated larvae. The reduction percentage found in the present study was much lower than that reported in previous studies for jirds ${ }^{1}$ or mice $^{3}$ immunized with irradiated larvae. It is difficult to make comparisons among these studies because of the different experimental protocols used. Furthermore, the recovery rate of worms from control animals in the previously mentioned studies was approximately $15 \%$, whereas in the present study $65 \%$ of larvae inoculated into control mice were recovered. This difference in parasite recovery may effect the interpretation of relative immunization success observed for the different protocols. However, it may be concluded that $B$. malay $i$ 
larvae are susceptible to immune elimination in experimental rodent hosts.

Larvae implanted in immunized mice grew in length when compared to L-3 measured directly after emergence from the mosquito. The rate of growth in immunized mice was, however, significantly less than that seen for larvae implanted in control mice. It was further demonstrated that all of the L-3 implanted in immunized mice failed to develop into L-4. Growth retardation or arrested development of nematodes in immunized hosts has been reported for several species ${ }^{14}$ including Ascaris suum, ${ }^{15}$ Heligmosomoides polygyrus, ${ }^{16}$ and the filarial worms Litomosoides carinii, ${ }^{17.18}$ D. viteae, ${ }^{7.8}$ and $D$. immitis. ${ }^{10}$ It remains unknown whether $B$. malayi larvae in immunized mice have been subjected to permanently arrested development and will therefore remain as L-3, or if their development and growth is retarded but will eventually yield adult worms.

The relationship between immune-mediated retardation of larval development or growth and immune-mediated killing of larvae is unclear. There is evidence that the 2 phenomena are unrelated. A. suum larvae with growth retardation recovered from immune mice resumed their growth when transferred to non-immune mice. ${ }^{15}$ This finding suggests that the growth retardation of A. suum larvae does not have a permanent deleterious effect on the larvae. Jirds immunized against $D$. viteae with live or dead larvae eliminated significant portions of challenge infections. However, larval growth retardation was only seen in challenge infections recovered from jirds immunized with live larvae, but not in those immunized with dead larvae. ${ }^{7}$ Furthermore, if jirds were immunized with irradiated $D$. viteae larvae and the challenge infections were allowed to persist until adults developed, stunted growth was observed in the adult worms recovered from immunized jirds. ${ }^{19}$ These findings suggest that growth of $D$. viteae in jirds immunized with live larvae is diminished from L-3 to adult worms, but that development is unimpeded. Furthermore, killing and growth retardation of larvae appear to occur independently.

There is also evidence which suggests that immune-mediated retardation and killing of larvae are different aspects of a single phenomenon. Larval growth retardation was observed as a prelude to the elimination of $D$. immitis larvae from immunized dogs, ${ }^{10}$ and $D$. viteae larvae from immunized jirds. ${ }^{8}$ Differences in susceptibility to immune reactions based on the larval phase of development were observed in both cases. ${ }^{8 .}{ }^{20}$ It was hypothesized that the protective immune response acts by retarding larval development at a stage with enhanced susceptibility to immune elimination. This would allow immune effector mechanisms sufficient time to interact with the susceptible stages.

Antibodies reactive with the internal and external antigens of L-3 and L- 4 were present in mice after immunization and at significantly higher levels after challenge. Control mice developed antibodies to the internal components but not the surface antigens following challenge. A similar finding of elevated antibody responses to L-3 surface antigens following challenge has been reported for jirds immunized against $B$. malayi. ${ }^{1}$ The fact that immune mice developed antibody responses to the larval surface whereas the controls did not suggests that surface antigens may be instrumental in inducing protective immunity. Additionally, the finding that both L-3 and L- 4 antigens elicited antibody responses suggests that both of these antigenic sources must be investigated to determine their relative roles in the induction of protective immunity. This conclusion is supported by the report that either L-3 or L-4 were capable of immunizing mice to infection with larval B. malayi. ${ }^{4}$

The mechanism by which larval $B$. malayi are immunologically eliminated has been investigated in several studies. Spleen cells, but not serum, from immunized BALB/c mice were shown to be effective at transferring protective immunity to the larvae of $B$. malayi, thus implicating a cellular immune response. ${ }^{21}$ Death of $B$. malayi larvae implanted in diffusion chambers in $M$. natalensis, rats, and jirds was found to be correlated with the presence of cells within the diffusion chambers. The number of cells found within a diffusion chamber was negatively correlated by species to percent larval survival. If the diffusion chambers were constructed in a manner that would not permit cells to enter, larvae survived regardless of the host in which they were implanted. ${ }^{13}$ In the present study, the diffusion chambers used were covered with membranes that allowed cells unimpeded entry, yet finding cellular adherence to either live or dead larvae was a rare occurrence. Another mechanism for larval $B$. malayi destruction has been described based on results obtained from immunized jirds. Dead or dying larvae from chal- 
lenge infections were observed within nodules in immunized but not control jirds. Eosinophils were found in close association with the moribund larvae. Based on the reported presence of antibodies reactive with the L-3 larval surface, it was suggested that challenge larvae were being eliminated by an antibody dependent eosinophil-mediated mechanism. ${ }^{22}$

The mechanism by which larval development is retarded is unknown. It has been demonstrated that retarded development and stunting of $H$. polygyrus larvae is mediated by antibody directed at excretory/secretory products and not to surface antigens. ${ }^{16} \mathrm{~A}$ similar mechanism may exist for $B$. malayi.

The present study demonstrates that BALB/c mice can be immunized against infection with B. malayi. The immunity is characterized by a reduction in parasite survival, growth, and development. Although an association between larval killing and antibody to larval surface antigens was observed, the mechanisms of protective immunity and the antigens capable of inducing protective immunity remain to be determined.

Financial support: University of Wisconsin-Madison, Madison. WI.

Authors' addresses: David Abraham, Department of Microbiology, Thomas Jefferson University, Philadelphia, PA. Robert B. Grieve, Department of Pathology, Colorado State University, Fort Collins, CO. Jon M. Holy. Department of Comparative Biosciences, and Bruce M. Christensen, Department of Veterinary Science, University of Wisconsin-Madison, Madison, WI.

Reprint requests: David Abraham, Department of Microbiology, Thomas Jefferson University, Philadelphia, PA 19107.

\section{REFERENCES}

1. Yates JA, Higashi GI, 1985. Brugia malayi: vaccination of jirds with 60 cobalt-attenuated infective stage larvae protects against homologous challenge. Am J Trop Med Hyg 34: 1132-1137. UI:86212801

2. Kazura JW, Cicirello H, McCall JW, 1986. Induction of protection against Brugia malayi infection in jirds by microfilarial antigens. $\mathrm{J} \mathrm{Im}$ munol 136: 1422-1426. UI:86113428

3. Hayashi Y, Noda K. Shirasaka A, Nogami S, Nakamura M, 1984. Vaccination of BALB/c mice against Brugia malayi and $B$. pahangi with larvae attenuated by gamma irradiation. Jpn J Exp Med 54: 177-181. UI:85083658

4. Carlow CK, Philipp M, 1987. Protective immunity to Brugia malayi larvae in BALB/c mice: potential of this model for the identification of protective antigens. Am J Trop Med Hyg 37: 597-604. UI:88074926

5. Court JP, 1982. A diffusion chamber technique for detecting compounds with clinical prophylactic activity against Brugia pahangi. Tropenmed Parasitol 33: 83-86. UI:82278543

6. Strote G, 1985. Development of infective larvae of Onchocerca volvulus in diffusion chambers implanted into Mastomys natalensis. Trop Med Parasitol 36: 120-122. UI:85272110

7. Tanner M, Weiss $N, 1981$. Dipetalonema viteae (Filarioidea): development of the infective larvae in micropore chambers implanted into normal, infected and immunized jirds. Trans $R$ Soc Trop Med Hyg 75: 173-174. UI:81275977

8. Abraham D, Weiner DJ, Farrell JP, 1986. Protective immune responses of the jird to larval Dipetalonema viteae. Immunology 57: 165-169. UI:86110347

9. Abraham D, Grieve RB, Mika-Grieve M, Seibert BP, 1988. Active and passive immunization of mice against larval Dirofilaria immitis. J Parasitol 74: 275-282. UI:88187960

10. Grieve RB, Abraham D, Mika-Grieve M, Seibert $\mathrm{BP}, 1988$. Induction of protective immunity in dogs to infection with Dirofilaria immitis using chemically-abbreviated infections. Am J Trop Med Hyg 39: 373-379. UI:89048054

11. Mak JW, Lim PK, Sim BK, Liew LM, 1983. Brugia malayi and $B$. pahangi: cultivation in vitro of infective larvae to the fourth and fifth stages. Exp Parasitol 55: 243-248. UI:83157996

12. Delves CJ, Howells RE, 1985. Development of Dirofilaria immitis third stage larvae (Nematoda: Filarioidea) in micropore chambers implanted into surrogate hosts. Trop Med Parasitol 36: 29-31. UI:85218263

13. Chandrashekar R, Rao UR, Parab PB, Subrahmanyam D, 1986. Brugia malayi: rat cell interactions with infective larvae mediated by complement. Exp Parasitol 62: 362-369. UI: 87054503

14. Ogilvie BM, De Savigny D, 1982. Immune response to nematodes. Cohen S, Warren KS, eds. Immunology of parasitic infections. Oxford: Blackwell Scientific Publications.

15. Crandall CA, Arean VM, 1964. In vivo studies of Ascaris suum larvae planted in diffusion chambers in immune and non-immune mice. J Parasitol 50: 685-688.

16. Ey PL, 1988. Heligmosomoides polygyrus: retarded development and stunting of larvae by antibodies specific for excretory/secretory antigens. Exp Parasitol 65: 232-243. UI:88167068

17. Scott JA, Macdonald EM, 1958. Immunity to challenging infections of Litomosoides carinii produced by transfer of developing worms. $J$ Parasitol 44: 187-191.

18. Weiner DJ, Abraham D, D'Antonio R, 1984. Litomosoides carinii in jirds (Meriones unguicullatus): ability to retard development of challenge larvae can be transferred with cells and serum. $J$ Helminthol 58: 129-137. UI:84265880 
19. Lucius R, Ruppel A. Diesfeld HJ, 1986. Dipetalonema viteae: resistance in Meriones unguiculatus with multiple infections of stage-3 larvae. Exp Parasitol 62: 237-246. UI:86301033

20. Abraham D, Grieve RB, Mika-Grieve M, 1988. Dirofilaria immitis: surface properties of thirdand fourth-stage larvae. Exp Parasitol 65: 157167. UI:88167060
22. Yates JA, Higashi GI, 1986. Ultrastructural observations on the fate of Brugia malayi in jirds previously vaccinated with irradiated infective stage larvae. Am J Trop Med Hyg 35: 982-987. UI:87023577 